\title{
云南温泉蓝藻多样性研究*
}

\author{
邓新晏 许继宏 \\ (云南大学生物系, 昆明 650091)
}

摘 要 云南温泉数量多, 分布广, 可划分为低温温泉、温泉、热泉和沸泉 4 种类型。生活在这些温泉中 的蓝藻不仅群落类型不同, 而且蓝藻区系与西藏、四川、印度等热带和亚热带地区具有一定的相似性。 本文报道云南温泉蓝藻 89 种, 分录于 3 纲 4 目 7 科 21 属。根据不同温泉类型的生态环境, 初步分析了 温泉蓝藻的群落结构、区系组成、分布特点,并对生物物种多样性和环境因素的关系进行了讨论。

关键词 温泉蓝藻, 物种多样性, 云南

Diversity study of thermal cyanophytes in Yunnan/Deng Xinyan , Xu Jihong//CHINESE BIODIVERSITY. - $1997,5(2) \quad 95 \sim 103$

There are a great deal of euthermes which distribute widely in Yunnan Province. The euthermes can be divided into four types : chliarothermes, euthermes, acrothermes and hyperthermes. Cyanophytes in these euthermes are different in the types of population ,and also their flora are similar to those of in the tropical and subtropical areas such as Xizang and Sichuan Provinces of China and India etc. In this paper , 89 species of thermal cyanophytes in Yunnan were studied. These species belong to 21 gerera, 7 families, 4 orders and 3 classes. The structures of their population , flora and distribution as well as the relationship between species diversity and the environmental factors were analysed and discussed.

Key words thermal cyanophytes, species diversity, Yunnan Province

Author's address Department of Biology , Yunnan University , Kunming 650091

引言

云南温泉水温在 $50{ }^{\circ} \mathrm{C}$ 以上的有 115 个, 最高水温可达 $90{ }^{\circ} \mathrm{C}^{[1]}$ 。由于地质结构复杂, 云南 温泉不仅数量大, 而且生态环境独特:有的矿化度很高, 有的呈极酸性, 有的含放射性镭元素。 在这些温泉中生活着极为丰富的藻类植物, 特别是温泉蓝藻。

根据温泉水温的高低, 许多藻类学工作者将温泉划分为 4 种类型 ${ }^{[3]}$ : 水温 $18 \sim 28{ }^{\circ} \mathrm{C}$ 为低 温温泉; 水温 $28 \sim 45{ }^{\circ} \mathrm{C}$ 为温泉; 水温 $45 \sim 65{ }^{\circ} \mathrm{C}$ 为热泉 ;水温 $65{ }^{\circ} \mathrm{C}$ 以上为沸泉。

$1992 \sim 1995$ 年间，我们对云南省宜良县的汤池温泉(采标本 5 号)，腾冲县的腾冲热海温 泉、黄瓜箐温泉 (采标本 27 号) , 洱源县的九台温泉、火焰山温泉,下山口温泉、牛街温泉 (采标 本 12 号)，下关温泉 (采标本 3 号) ,中甸县温泉等 5 个县市的近 10 个温泉进行了重点调查, 采 集标本 48 号, 其中低温温泉标本 2 号, 温泉标本 8 号, 热泉标本 17 号, 沸泉标本 21 号。与此 同时, 对温泉的水温、 $\mathrm{pH}$ 值、海拔高度进行了测定。最低水温 $27{ }^{\circ} \mathrm{C}$, 最高水温 $90{ }^{\circ} \mathrm{C}$ (腾冲热 海鼓鸣泉) ,多数在 $45 \sim 70{ }^{\circ} \mathrm{C}$ 范围内 $\mathrm{pH}$ 最低值为 4.5 (汤池温泉), 最高达到 9.0 (腾冲热海 温泉)，一般在 $6.5 \sim 8.0$ 之间，呈弱酸性或中性(表 1 )。 
表 1 各地温泉藻类标本及主要生境

Table 1 The specimen and ecological environment of euthermes algae on every spot

\begin{tabular}{|c|c|c|c|c|}
\hline $\begin{array}{c}\text { 标本号 } \\
\text { number of specimen }\end{array}$ & $\begin{array}{c}\text { 采集地 } \\
\text { sites of collection }\end{array}$ & $\mathrm{pH}$ & $\begin{array}{c}\text { 水温 }\left({ }^{\circ} \mathrm{C}\right) \\
\text { water temperature }\end{array}$ & $\begin{array}{c}\text { 海拔 }(\mathrm{m}) \\
\text { height }\end{array}$ \\
\hline \multicolumn{5}{|c|}{ 低温温泉 ( Chliarothermes) } \\
\hline YN9329 & 腾冲热海眼镜泉旁 & 6.5 & 27 & 1647 \\
\hline YN9436 & 下关温泉旁小水沟内 & 8.0 & 28 & 2080 \\
\hline \multicolumn{5}{|l|}{ 温泉 (Euthermes) } \\
\hline YN93006 & 腾冲热海大滚锅石壁 & 7.6 & 35 & \\
\hline YN93014 & 腾冲热海仙人澡塘石壁 & 8.0 & 40 & \\
\hline YN93015 & 腾冲热海仙人澡塘旁 & 8.0 & 42 & \\
\hline YN9321 & 腾冲黄瓜箐温泉旁 & 6.5 & 31 & \\
\hline YN9322 & 腾冲黄瓜箐温泉旁水沟内 & 7.0 & 34 & \\
\hline YN9325 & 腾冲热海怀胎井下沟内 & 6.5 & 36 & \\
\hline YN9326 & 腾冲热海珍珠泉旁 & 6.5 & 45 & \\
\hline YN9333 & 腾冲热海蛤蟆嘴河内 & 7.0 & 36 & \\
\hline \multicolumn{5}{|l|}{ 热 泉 (Acrothermes) } \\
\hline YN93003 & 汤池温泉河边石壁 & 4.5 & 46 & 1841 \\
\hline YN93004 & 汤池招待所抽水站旁石头上 & 5.0 & 50 & \\
\hline YN93005 & 汤池温泉抽水站口 & 5.0 & 50 & \\
\hline YN93007 & 腾冲热海大滚锅旁 & 7.9 & 65 & \\
\hline YN93008 & 腾冲热海大滚锅旁石头上 & 7.5 & 64 & \\
\hline YN93009 & 腾冲热海大滚锅 $200 \mathrm{~m}$ 处水塘 & 7.0 & 62 & \\
\hline YN93010 & 腾冲热海怀胎井内 & 7.9 & 64 & \\
\hline YN93012 & 腾冲热海鼓鸣泉旁水沟内 & 8.5 & 57 & \\
\hline YN93017 & 腾冲热海蛤蟆嘴 50 m 处一温泉 & 7.0 & 62 & \\
\hline YN93018 & 腾冲热海蛤蟆嘴 $100 \mathrm{~m}$ 处一温泉 & 7.0 & 60 & \\
\hline YN93019 & 腾冲热海蛤蟆嘴 & 7.5 & 60 & \\
\hline YN9327 & 腾冲热海珍珠泉旁 & 6.5 & 57 & \\
\hline YN9328 & 腾冲热海眼镜泉石壁 & 8.5 & 60 & \\
\hline YN9446 & 洱源县下山口温泉 (停车场内) & 6.5 & 60 & \\
\hline YN9447 & 洱源下山口温泉出水口石壁 & 6.5 & 58 & \\
\hline YN9448 & 洱源下山口温泉旁小水沟内 & 6.5 & 55 & \\
\hline \multicolumn{5}{|l|}{ 沸泉 ( Hyperthermes) } \\
\hline YN93001 & 汤池温泉铁水管内壁 & 4.5 & 68 & \\
\hline YN93002 & 汤池温泉口石壁 & 5.0 & 72 & \\
\hline YN93011 & 腾冲热海鼓鸣泉 & 8.5 & 99 & \\
\hline YN93013 & 腾冲热海鼓鸣泉旁水沟内 & 8.5 & 70 & \\
\hline YN93016 & 腾冲热海蛤蟆嘴 $300 \mathrm{~m}$ 处一温泉 & 7.0 & 70 & \\
\hline YN9320 & 腾冲热海蛤蟆嘴 60 m 处一温泉 & 7.5 & 70 & \\
\hline YN9323 & 腾冲热海蛤蟆嘴附近一温泉 & 7.0 & 72 & \\
\hline YN9324 & 腾冲热海蛤蟆嘴 $250 \mathrm{~m}$ 处一温泉 & 7.0 & 82 & \\
\hline YN9330 & 腾冲热海至仙人澡塘间水沟内 & 9.0 & 66.5 & \\
\hline YN9331 & 腾冲热海距蛤蟆嘴 $300 \mathrm{~m}$ 处一温泉 & 7.6 & 69 & \\
\hline YN9332 & 腾冲热海大滚锅澡塘旁 & 7.9 & 70 & \\
\hline YN9434 & 下关温泉泉涌处石壁 & 7.5 & 72 & \\
\hline YN9435 & 下关温泉小股泉水渗出处石壁 & 8.0 & 70 & \\
\hline YN9437 & 洱源九台温泉 & 6.5 & 68 & \\
\hline YN9438 & 洱源九台温泉旁水沟内 & 6.5 & 66 & \\
\hline YN9439 & 洱源九台温泉旁石头上 & 6.5 & 66 & \\
\hline YN9440 & 洱源城关镇温泉出水口石壁 & 7.5 & 77 & \\
\hline YN9441 & 洱源城关镇温泉附近水塘内 & 7.0 & 75 & \\
\hline YN9442 & 洱源火焰山温泉泉涌处石壁 & 7.5 & 80 & \\
\hline RN9443 & 洱源火焰山温泉旁小塘内 & 8.0 & 66 & \\
\hline YN9444 & 洱源县牛街温泉 & 7.5 & 82 & \\
\hline YN9445 & 洱源县牛街温泉泉涌处石壁 & 7.0 & 80 & \\
\hline
\end{tabular}

按我省自然地理区划分的气候带看，腾冲属热带北缘地带; 宜良汤池、下关、洱源属高原亚 热带北部地带; 中甸属青藏高原东南缘寒温带 ${ }^{\lceil 2 〕 。 ~}$

云南温泉藻类资源丰富, 种类多,分布广, 但正式报道的甚少。李尧英 ${ }^{[3,4]}$ 报道过云南温 泉蓝藻 15 种。 
参考过杨钦州先生早年写的 云南下关温泉藻类植物的调查”报告。

\section{2 群落特点与种类组成}

\section{1 群落特点}

不同温泉或同一温泉的不同环境中, 无论是单细胞或丝状种类的温泉蓝藻, 往往都能形成 较厚的质地和形状不同的胶质群落, 这是温泉蓝藻一个重要的外部特征。此外, 颜色也是温泉 蓝藻群落外观上的一个显著特征。群落的形态大体有 5 种 :(1) 壳状群落 主要由线形粘杆 藻 (Gloeothece linearis) 形成的单优势种群落, 细胞少数到多数聚集在一起形成厚的胶被, 群体 之间的胶质相互联结, 胶质中混有泥土或沉积物, 形成硬壳状群落。群落有明显分层现象, 且 呈橄榄绿色或红色; (2) 皮状群落 主要以颤藻属 (Oscillatoria) 和鞘丝藻属 (Lyngbya) 等丝状 藻类为优势组成。该两属的植物体均为不分枝的单条藻丝, 但藻丝往往扭曲。颤藻的藻丝能 滑动, 鞘丝藻的藻丝能规则或不规则地螺旋缠绕, 故形成比较厚的坚固的皮状群落, 群落有的 分层, 有的不分层, 无色, 黄色到褐色; (3) 胶质群落 这是一种普遍的群落, 绝大部份温泉藻 类都能形成胶块状群体，但尤以双歧藻属 (Scytonema) 和单歧藻属 (Tolypothrix) 为主所形成的 群落最为明显。藻丝具假分枝, 相互缠绕。群体胶被一般分层次, 胶鞘坚固, 群落呈黄褐色或 绿色; (4) 膜状群落 主要由席藻属 (Phormidium) 和眉藻属 (Calothrix) 植物组成。群体胶质衣 鞘厚, 略硬, 彼此粘连, 相互交织成膜状的群落。群落分层明显, 呈棕黑色; (5) 皮壳状群落 是一种复合型群落, 具皮状群落和壳状群落的特征。以线形粘杆藻形成的壳状层居下, 并附于 基质上,而以丝状藻类形成的皮状层在上,是群落的主要部份。

\section{2 种类组成}

云南温泉蓝藻迄今共记录 89 种, 分录于 3 纲 4 目 7 科 21 属。其中颤藻属 23 种, 占总种 数的 $26 \%$; 席藻属 21 种, 占 $23 \%$;聚球藻属 8 种, 色球藻属 7 种, 分别占 $9 \%$ 和 $8 \%$ 鞘丝藻属 6 种, 占 $7 \%$;粘球藻属, 集胞藻属, 眉藻属各 3 种; 束藻属、伪枝藻属各 2 种, 其它各属只有 1 种。 可见，㗜藻种类最多，其次是席藻，再次是色球藻、聚球藻和鞘丝藻 ( 表 2 )。

\section{3 分布特点与生态性质}

\section{1 各地区的种群分布和环境特点}

根据过去的资料和本次鉴定, 这些地区的种群分布概况是: (1)下关温泉 16 属 58 种; (2) 吉沙叉路口温泉 4 属 5 种; (3) 中甸基吕热水潭 4 属 4 种; (4) 宜良汤池温泉 15 属 36 种; (5) 腾冲县热海温泉 14 属 56 种,黄瓜箐温泉 14 属 46 种; (6) 洱源县九台温泉 15 属 33 种城关镇 温泉 10 属 24 种,火焰山温泉 9 属 22 种, 牛街温泉 12 属 28 种,下山口温泉 17 属 44 种。上述 地区，除吉沙叉路口温泉及中甸基吕热温泉因当时采集的标本不多,种类较少外，其他各地属 种都十分丰富，这除了与采集的标本数量有关，也同这些地区的特殊生态环境是分不开的。 如腾冲热海温泉, 素有 云南温泉甲中国，腾冲温泉甲云南”之称。我们所采集的标本既有热气 腾腾的 热海温泉”, 又有一形似蛤蟆张嘴吐热的 蛤蟆泉”, 还有叮咚作响的 鼓鸣泉”, 满池 吐着气泡的珍珠泉”, 以及两井并列的 眼镜泉”和温度近沸点的 大滚锅”。

腾冲温泉属于硫磺泉, 泉水中既没有硝酸盐, 又无铵盐, 大量蓝㩰生长需要的氮, 或从空气 中同化而来，或间接由共生的细菌同化游离氮供给。生长在这些温泉中的主要种类有灿烂颤 藻和米纳瓦聚球藻大型变种。云南下关温泉地处横断山脉点苍山与无量山之间的峡谷中, 由 强烈的喜马拉雅运动而形成, 海拔 $2080 \mathrm{~m}, \mathrm{pH} 8.0 \sim 9.0$, 常为 9.0 环境特殊, 温泉中含有较高 
表 2 云南温泉蓝藻的种类及分布

Table 2 The list of species and distribution of thermal cyanophytes in Yunnan Province

采集地点 Sites of collection

水 温 $\left({ }^{\circ} \mathrm{C}\right)$ Water temperature

种类 Species $\mathrm{pH}$

温泉隐球藻 (Aphanocapsa thermalis)

巢形隐杆藻 (Aphanothece nidulans)

膨胀色球藻温泉变种

(Chroococcus turgidus var. thermalis)

惠氏色球藻 (C. westii)

微小色球藻 (C. minutus)

微小色球藻温泉变种

(C. minutu var. thermalis)

内生色球藻大型变种

( C. endophyticus var. major)

湖沼色球藻 (C. limneticus)

小形色球藻 (C. minor)

胶质粘球藻 (Gloeocapsa gelatinosa)

居氏粘球藻 (G. kutzingiana)

微小粘球藻 (G. minutula)

线形粘球藻 (Gloeothece linearis)

圆胞束球藻心形变种 (Gomphosphaeria aponina var. cordifomis)

点形平裂藻 (Merismopedia punctata)

水生集胞藻 (Synechocystis aquatilis)

极小集胞藻 (S. minuscula)

惠氏集胞藻 (S. willei)

铅色聚球藻 (Synechococcus lividus)

米纳瓦聚球藻 (S. minervae)

米纳瓦聚球藻大型变种

( $S$. minervae var. major)

非凡聚球藻 (S. eximius)

细长聚球藻极粒变种

( $S$. elon gatus var. emphigramilanus)

摆动聚球藻 (S. ambiguns)

小聚球藻 ( $S$. parvus)

淡兰色聚球藻 (S. sublividus)

圆柱管狍藻 (Chamaesiphon cylindricus)

栖霞鞘丝藻 (Lyngbya digueti)

纤细鞘丝藻 (L. gracilis)

黄色鞘丝藻 (L. lutea)

赖氏鞘丝藻 (L. lagerheimii)

林氏鞘丝藻 (L.ferruginea)

美丝鞘丝藻 (L.perelegans)

两栖颤藻 (Oscillatoria amphibia)

伪双点颤藻 (O. pseudogeminata)

伪双点颤藻单粒变种 (O. pseudogeminata var. unigra nulata)

暗蓝颤藻 (O. coerulescens)

尖细颤藻 (O. acuminata)

美丽颤藻 (O.formosa)

钻头颤藻 (O. terebriformis)

绿色颤藻 (O. chlorina)

奥克尼颤藻 (O. okeni)

爬行颤藻 (O. animalis)

狭细颤藻 (O. angustissima)
下关温泉 吉沙叉路口温泉 中甸基吕热水潭 宜良汤池温泉

Xiaguan Jishachalukou Zhongdianjilu Yiliangtangchi

euthermes euthermes euthermes euthermes
$28 \sim 72$
24
62
$46 \sim 72$

$7.5 \sim 8.0$

8.0

4. $5 \sim 5.0$
$+$

$+$

$+$

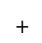

$+$

$+$

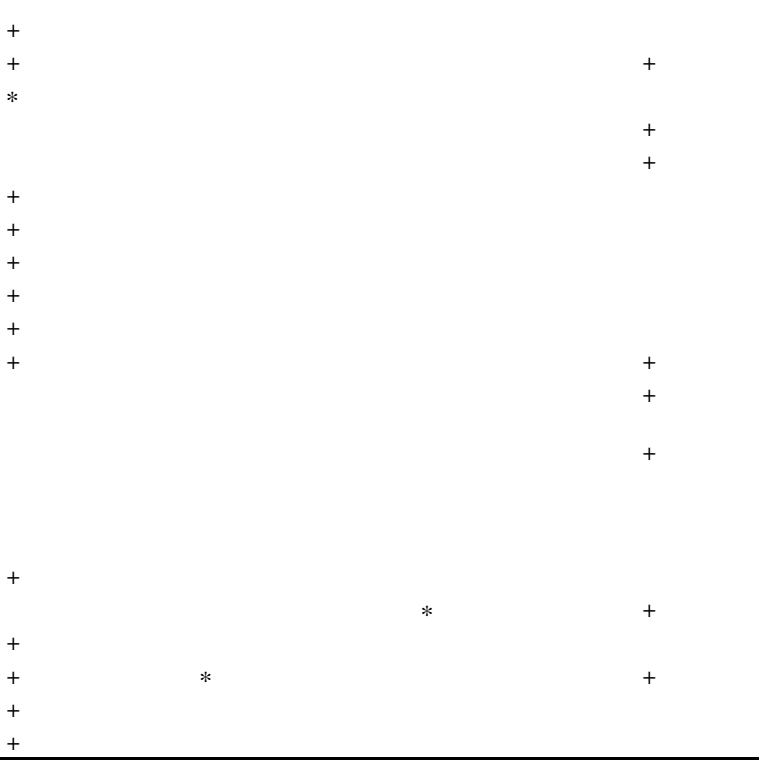




\begin{tabular}{|c|c|c|c|c|c|c|}
\hline \multirow[t]{2}{*}{ 腾 } & \multirow{2}{*}{ County } & \multirow{2}{*}{\multicolumn{2}{|c|}{ 洱 }} & 源 & \multirow[t]{2}{*}{ 县 } & \\
\hline & & & & Eyuan County & & \\
\hline $\begin{array}{l}\text { 热海温泉 } \\
\text { rehai } \\
\text { euthermes }\end{array}$ & $\begin{array}{c}\text { 黄瓜箐温泉 } \\
\text { Huanggaaqing } \\
\text { euthermes }\end{array}$ & $\begin{array}{c}\text { 九台温泉 } \\
\text { Jiutai } \\
\text { euthermes }\end{array}$ & $\begin{array}{c}\text { 城关镇温泉 } \\
\text { Chengguazhen } \\
\text { euthermes }\end{array}$ & $\begin{array}{c}\text { 火焰山温泉 } \\
\text { Huoyanshan } \\
\text { euthermes }\end{array}$ & $\begin{array}{c}\text { 牛街温泉 } \\
\text { Niujie } \\
\text { euthermes }\end{array}$ & $\begin{array}{c}\text { 下山口温泉 } \\
\text { Xiashankou } \\
\text { euthermes }\end{array}$ \\
\hline $27 \sim 99$ & $31 \sim 82$ & $66 \sim 88$ & $75 \sim 77$ & $65 \sim 80$ & $80 \sim 82$ & $55 \sim 60$ \\
\hline $6.5 \sim 9.0$ & $6.5 \sim 7.0$ & 6.5 & $7.0 \sim 7.5$ & $7.5 \sim 8.0$ & $7.0 \sim 7.5$ & 6.5 \\
\hline+ & + & + & + & + & + & $\begin{array}{l}+ \\
+ \\
+\end{array}$ \\
\hline & + & & & & & + \\
\hline+ & + & & & & & \\
\hline+ & + & & & & & \\
\hline+ & + & & & + & & + \\
\hline+ & + & & & & & \\
\hline+ & + & & & & & \\
\hline+ & + & & & & & \\
\hline+ & + & & & & & \\
\hline+ & & & & & & + \\
\hline+ & + & $\begin{array}{l}+ \\
+\end{array}$ & + & & + & $\begin{array}{l}+ \\
+\end{array}$ \\
\hline+ & + & & & & & \\
\hline+ & + & & & & & + \\
\hline+ & & + & & & + & + \\
\hline+ & + & & & + & + & \\
\hline+ & & + & & & & + \\
\hline+ & + & + & + & + & + & + \\
\hline+ & + & & & + & + & \\
\hline$+*$ & + & + & + & & + & \\
\hline+ & & & & & & \\
\hline+ & & + & & & & + \\
\hline & & + & + & + & + & + \\
\hline+ & + & + & + & + & + & \\
\hline+ & + & & & + & + & \\
\hline+ & & + & & + & + & + \\
\hline+ & + & & & & & \\
\hline & + & & & & & \\
\hline & + & & & & & \\
\hline & + & & & & & \\
\hline & + & & & & & \\
\hline+ & + & + & + & + & & + \\
\hline+ & + & & + & & + & + \\
\hline+ & + & & & & & + \\
\hline$*$ & + & & & + & + & \\
\hline+ & + & + & & + & & + \\
\hline$*+$ & + & + & + & & + & + \\
\hline & & + & & & & + \\
\hline & + & & & & & + \\
\hline & & + & + & + & + & + \\
\hline
\end{tabular}




\begin{tabular}{|c|c|c|c|c|}
\hline 多育颤藻 $(O$. prolifica $)$ & + & & & \\
\hline 灿烂颤藻 (O. splendida) & & & & \\
\hline 柔细颤藻 $($ O. subtillissima $)$ & $*+$ & & & \\
\hline 沼泽颤藻（O. limnetica） & & & & + \\
\hline 双点颤藻（O.geminata） & + & & & \\
\hline 明尼苏达颤藻 (O. minnesotensis) & + & & & + \\
\hline 光颤藻 $\quad(O$. nitila $)$ & + & & & + \\
\hline 微红颤藻 $(O$. rubesuns $)$ & + & & & \\
\hline 尖头颤藻 (O. acutissima) & & & & + \\
\hline 极小颤藻 （O. minima $)$ & & & & \\
\hline 泥泞颤藻（O. limosa $)$ & & & & \\
\hline 亚平滑颤藻 (O. subiformis) & + & & & \\
\hline 粗壮席藻 (Phormidium valderianum) & + & * & & + \\
\hline 分层席藻 $\quad(P$. laminosum $)$ & & & & + \\
\hline 土生席藻（P. mucicola ) & & & * & \\
\hline 坑形席藻（P. foveolarum ) & & & & + \\
\hline 纸形席藻 (P. papyraceum $)$ & + & & & \\
\hline 韧氏席藻 $\quad$ (P. retzii $)$ & + & & & \\
\hline 胶质席藻 $\quad($ P. gelatinosum $)$ & + & & & + \\
\hline 纤细席藻 $\quad(P$. tenue $)$ & & & & + \\
\hline 鱼腥藻形席藻 (P. anabaenaceum) & & & & + \\
\hline 短席藻 $\quad(P$. curtum $)$ & + & & & \\
\hline 紫席藻 (P. purpurascens) & + & & & \\
\hline 皮状席藻 (P. corium) & + & & & \\
\hline 软席藻 $\quad(P$. molle $)$ & + & & & \\
\hline 脆席藻 (P. fragile) & + & & & \\
\hline 洪水席藻 $\quad(P$. inundatum $)$ & + & & & \\
\hline 雷氏席藻（P. retzii) & + & & & + \\
\hline 污棕席藻 (P. luridum) & + & & & \\
\hline 易碎席藻（P. fragile) & + & & & \\
\hline 亚丁席藻 (P. jadinianum) & + & & & + \\
\hline 小席藻 $\quad($ P. tenule $)$ & + & & & + \\
\hline 峭壁束藻 (Symploca muralis) & + & & & + \\
\hline 孟氏束藻（S. meneghiniana ) & + & & & \\
\hline 沃克筒狍藻 (Cylindrospermum vouki) & + & & & \\
\hline 圆雉眉藻（Calothrix conica ) & + & & & \\
\hline 伊莱克眉藻（C. elenkinii） & + & & & \\
\hline 温泉眉藻 (C. thermalis) & + & & & + \\
\hline 温泉胶须藻 (Rivularia thermalis) & & & & + \\
\hline 奇异伪枝藻 (Scytonema mirabile) & + & & & \\
\hline 单歧伪枝藻 (S. tolypthrichoides) & + & & & \\
\hline 扭曲单歧藻（ Tolypethrix distoria ) & + & & & \\
\hline 马来西亚织线藻 (Plectonema malayensa) & + & & & \\
\hline 整洁粘囊藻（Myxosarcina concinna ) & + & & & \\
\hline 合 计 Total & 58 & 5 & 4 & 36 \\
\hline
\end{tabular}

*李尧英报导的种类 ; + 本次鉴定的种类

* Species reported by Li Raoying ; + Species identified this time

的矿物质、气体和丰富的养料,适应这种环境的柔细颤藻和淡蓝色聚球藻生长良好。而宜良汤 池温泉的海拔 $1841 \mathrm{~m} \mathrm{,pH} 4.5 \sim 5.0$,呈酸性, 胶质席藻等能较好地生长。由于不同温泉的物 理性质有较大的差异, 因此生长在这些环境中的生物不仅区系成分复杂, 而且呈现出生物物种 的多样性。

\section{2 温泉类型不同, 蓝藻种群存在着明显差异}

温泉是生物生活的特殊环境, 具有特殊的生物类群。温泉中的温度是生物生存的重要因 素。温度愈高, 能忍受的植物愈少。在超过 $50{ }^{\circ} \mathrm{C}$ 的热泉中生长的生物主要是蓝藻和细菌。

Geither ${ }^{[5]}$ 根据观察, 认为蓝藻能忍受的最高温度为 $69{ }^{\circ} \mathrm{C}$ 。Petersen ${ }^{[5]}$ 发现蓝藻在 $77{ }^{\circ} \mathrm{C}$ 时 还能生存。这次调查发现在 $90{ }^{\circ} \mathrm{C}$ 的温泉中仍有数种蓝藻生长, 而且在不同类型的温泉中有不 同的优势蓝藻种群。 


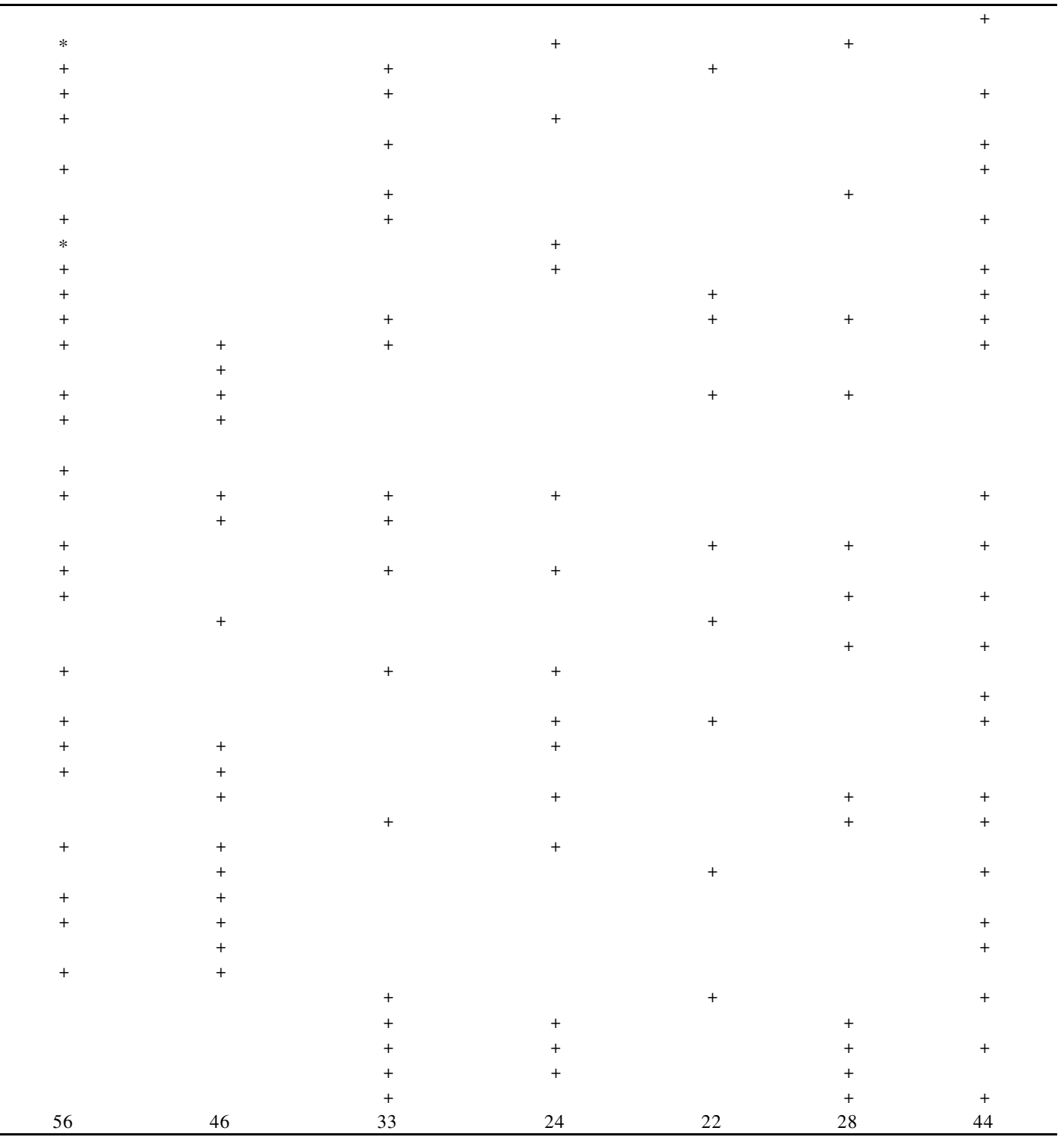

在低温温泉中的蓝藻有 11 种, 优势种类为: 惠氏色球藻, 湖泊色球藻, 尖细颤藻, 狭细颤 藻, 美丽颤藻和黄色鞘丝藻。

在温泉及热泉中的蓝藻有 44 种, 优势种类为: 膨胀色球藻温泉变种, 惠氏集矜藻, 铅色聚 球藻, 细长集球藻极粒变种, 爬行颤藻, 伪双点颤藻, 明尼苏达颤藻, 分层席藻, 纸形席藻和 温泉胶须藻。

沸泉中的蓝藻有 17 种, 优势种类为: 温泉隐球藻, 米纳瓦聚球藻, 淡兰色聚球藻, 坑形席 藻, 钻头颤藻。而铅色聚球藻, 极小集胞藻能生长在 $90{ }^{\circ} \mathrm{C}$ 的沸泉中。奥克尼颤藻, 粗壮席 藻，温泉眉藻对温度适应范围较广, 能生活在不同温度类型的温泉中。

3.3 典型的温泉蓝藻具有世界性分布,在云南不同类型的温泉中均能生长

从上述各地区温泉中生长的蓝藻来看, 虽然温泉的自然环境不同, 温泉的类型也不一样, 但由于它们都是生活在水温较高的特殊生境中, 是一群在极端环境下生长的原始生物; 双由 
于多数温泉在一年之中没有多大变化, 生长在这些温泉中的藻类不仅受气温的影响很小, 而且 在不同海拔高度的温泉中往往出现相同的优势种类。有人研究证明现在还具有与 100 多年前 所观察到的一样的植物 ${ }^{[5,11]}$ 。因此一些典型的温泉蓝藻对水温的适应范围大致相同, 成为世 界性分布的种类。例如铅色聚球藻在美国温泉中水温范围为 $50 \sim 65{ }^{\circ} \mathrm{C}^{\{15]}$, 在日本温泉中水 温范围是 $35 \sim 59{ }^{\circ} \mathrm{C}$ 。米纳瓦聚球藻在美国温泉中水温范围为 $40 \sim 70{ }^{\circ} \mathrm{C}, \mathrm{pH} 7.8 \sim 8.0$ 。非凡 聚球藻在美国温泉中水温范围为 $68.0 \sim 83.6{ }^{\circ} \mathrm{C}, \mathrm{pH} 4.5 \sim 5.3$ 。这些种类不仅在美国、日本有 发现 ${ }^{\{12.13\}}$, 在我国的西藏、云南的温泉中分布也很广泛, 水温范围为 $57 \sim 90{ }^{\circ} \mathrm{C}, \mathrm{pH} 4.5 \sim 8.5$ 之间, 是典型的温泉藻类。又如钻头颤藻在腾冲黄瓜等温泉中水温范围是 $31 \sim 34{ }^{\circ} \mathrm{C}, \mathrm{pH} 6.5$ $\sim 7.5$; 在宜良汤池温泉中水温范围是 $46 \sim 72{ }^{\circ} \mathrm{C}, \mathrm{pH} 4.5 \sim 5.0$;洱源下山口温泉中水温范围 是 $55 \sim 60{ }^{\circ} \mathrm{C}, \mathrm{pH} 5.0 \sim 8.0$; 在下关温泉中水温范围是 $32 \sim 72{ }^{\circ} \mathrm{C}, \mathrm{pH} 7.5 \sim 8.0$; 在吉沙叉路口 温泉中的水温为 $62{ }^{\circ} \mathrm{C}$ 。由此可见, 该种的水温范围为 $31 \sim 72{ }^{\circ} \mathrm{C}$, 但在水温 $34 \sim 60{ }^{\circ} \mathrm{C}, \mathrm{pH} 6.5$ $\sim 8.0$ 的温泉中生长最好, 这与在美国黄石公园发现的水温范围 $45 \sim 55{ }^{\circ} \mathrm{C}$ 和在日本温泉中的 水温范围 $41 \sim 58{ }^{\circ} \mathrm{C}$ 基本相一致 ${ }^{[14,15]}$

此外,在各地温泉中, 分布广, 生长旺盛的还有两栖颤藻、分层席藻和温泉眉藻等。

\section{4 讨论}

4. 1 云南温泉蓝藻与邻近地区种类比较, 具有一定的相似性

在云南的 89 种温泉蓝藻中, 有 11 种曾发现于西藏,有 7 种曾发现于四川,有 6 种曾发现 于印度, 有 2 种曾发现于斯里兰卡。由此可见该地区温泉蓝藻种类的多样性以及蓝藻区系在 地理分布上与西藏、四川、印度 ${ }^{[7,9,10]}$ 等热带和亚热带地区的密切关系 (表 3)。

表 3 云南温泉蓝藻与邻近地区种类的比较

Table 3 The comparison of thermal cyanophytes and species in Yunnan with border distriction

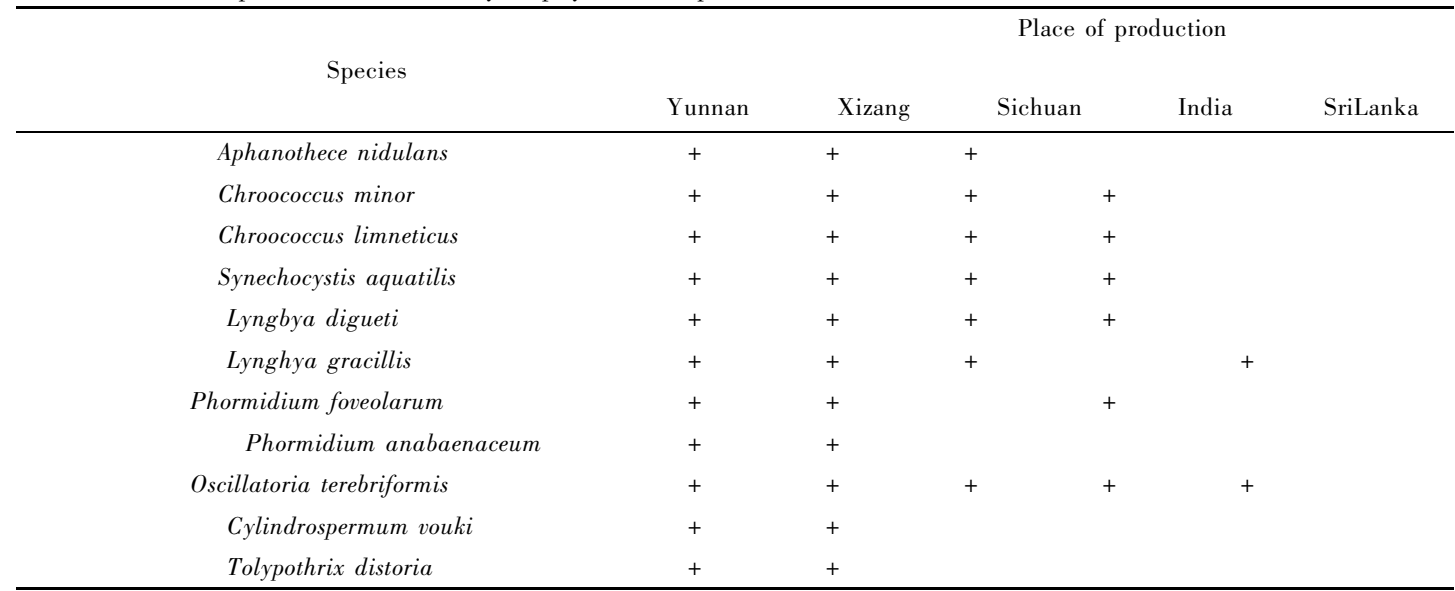

\section{2 云南温泉中的特有种类及首次报道的温泉蓝藻}

内生色球藻大型变种 (Chroococcus endophyticus var. major Li. ) 是李尧英同志 1985 年发表 的新变种, 标本采自横断山吉沙温泉, 水温 $24{ }^{\circ} \mathrm{C}$, 海拔 $3070 \mathrm{~m}, \mathrm{pH} 6.5$ 。我们在下关温泉水塘 中 (水温 $32{ }^{\circ} \mathrm{C}, \mathrm{pH} 8.0$ )、腾冲热海温泉眼镜泉边 (水温 $29{ }^{\circ} \mathrm{C}, \mathrm{pH} 6.5$ )、腾冲黄瓜箐温泉水池 内 (水温 $34{ }^{\circ} \mathrm{C}, \mathrm{pH} 7.0$ ) 也采到。其大小和形态同原来新变种基本相似。不同之处主要是群 体直径略小, 最大为 $25 \sim 35 \mu \mathrm{m}$, 最小的仅 $10 \sim 20 \mu \mathrm{m}$, 平均直径 $15 \sim 25 \mu \mathrm{m}$ 。

在这次报道的温泉蓝藻中, 有 74 种是云南首次报道的温泉蓝藻, 其中 20 种生长在非温泉 
的其它水环境中，也作过报道 ${ }^{[6,8]}$ 。云南有 54 种温泉蓝藻尚未正式报道。它们是 :Aphanocapsa thermalis ; Aphanothece nidulans ; Chroococcus minutus var. thermalis , C. westii ; Gloeocapsa minutula ; Gomphosphaeria aponina var. cordifomis ; Synechocustis minuscula , S. aquatilis ,S. willei ; Synechococcus lividus ,S. minervae ,S. eximius ,S. ambiguns ,S. parvus ; Chamaesiphon cylindricus ; Lyngbya lutea , L. lagerheimii ,L. ferruginea ,L. perelegans ; Oscillatoria pseudogeminata , O. pseudogemiata var. unigranulata , O. animalis , O. angustissima ,O. prolifica ,O. limnetica ,O. geminata ,O minnesotensis,$O$. nitila ,O. acutissima,$O$. subuiformis ; Phormidium foveolarum , P. papyraceum , $P$. retzii , P. tenue,$P$. purpurascens,$P$. anabaenaceum,$P$. curtum,$P$. corium,$P$. inundatum ,P. luridum , P. fiagile ,P. jadinianum ,P. tenule ;Symploca muralis ,S. meneghinila ; Calothrix conica ,C. elenkinii , C. thermalis ; Rivularia thermalis ; Scytonema mirabile, S. tolypothrichoides ; Tolypothrix distorta ; Plectonema malayensa; Myxosarcina concinna.

4.3 在上述种类中, 有的生境特殊, 有的结构复杂, 形成了独特的蓝藻区系。如巢形隐杆藻, 水温 $27{ }^{\circ} \mathrm{C}, \mathrm{pH} 6.5$ 植物体为团块状群体, 混生在颤藻中, 往往形成小的鸟巢形”;园胞束球 藻心形变种, 水温 $27 \sim 40{ }^{\circ} \mathrm{C}, \mathrm{pH} 7.0$ 细胞心脏形, 具胶质柄; 非凡聚球藻, 水温 $55 \sim 72{ }^{\circ} \mathrm{C}, \mathrm{pH}$ 8.0 细胞圆柱形, 单独存在或分裂时成对, 内含物均匀; 鱼腥藻形席藻, 水温 $27^{\circ} \mathrm{C}, \mathrm{pH} 8.0$, 常 和其它藻类混生, 藻丝在横壁处显著收䍀, 是西藏地区的特有种类; 圆雉眉藻, 水温 $35 \sim 70{ }^{\circ} \mathrm{C}$, $\mathrm{pH} 6.5 \sim 7.0$ ，丝状体基部稍膨大，异形胞球形基生；温泉胶须藻，水温 $31{ }^{\circ} \mathrm{C}, \mathrm{pH} 7.0$,植物体球 状, 藻丝放射状和簇生, 假分枝成 $\mathrm{V}$ ” 字形; 马来西亚织线藻, 水温 $72{ }^{\circ} \mathrm{C}, \mathrm{pH} 7.0$,植物体直 立，缠绕，假分枝成对，细胞横壁收缩，内含物具颗粒; 整洁粘囊藻, 水温 $68{ }^{\circ} \mathrm{C}, \mathrm{pH} 7.5$, 植物体 为规则的方圆群体, 个体胶被相互溶合, 群体胶被明显, 细胞半球形或多角形 ${ }^{[11.13]}$ 。

综上所述, 生长在特殊生境中的温泉蓝藻不仅具有独特的蓝藻区系, 而且具有温泉生物 特有的化学成分和特殊的构造。为什么它们的蛋白质在温度接近 $90{ }^{\circ} \mathrm{C}$ 时却不凝固, 这就不 仅仅是一般的生态问题, 而是涉及到原生质中凝固点的高低以及酶的活动等的生理问题。研 究这些生理现象, 对探讨蓝藻的起源具有非常重要的意义。

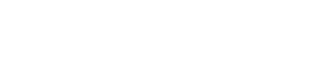

1 云南省环境保护局. 云南省环境质量报告书(试报). 1981 ,4 25

2 杨一光. 云南省综合自然区划. 北京: 高等教育出版社, 1990,112 213

3 李尧英. 西藏高原及横断山区的温泉蓝藻. 水生生物学报, 1985 3(9) 264 278

4 李尧英, 魏印心, 施之新等. 西藏藻类. 北京 科学出版社, 1992 21 115

5 B. 福迪著, 罗迪安译. 藻类学. 上海科学出版社, 1978, 399 401

6 钱澄宇, 邓新晏,王若南等. 滇池藻类植物调查研究. 云南大学学报(自然科学版), 1985,79 28

7 饶钦止. 西藏南部地区的藻类. 海洋与湖沼 ,1964 ,6(2) :169 192

8 朱浩然. 中国色球藻科志. 南京大学学报, 1963, (1) 93 200

9 李尧英. 西藏蓝藻门新植物. 植物分类学报, 1984 22(2): 167 174

10 饶钦止, 朱蕙忠, 李尧英. 珠穆朗玛峰地区的藻类. 见: 珠穆朗玛峰地区科学考察报告 $(1966 \sim 1968)$, 生 物与高山生理分册, 1974,92 126

11 Castenholz R W. The thermophilic Cyanophytes of Iceland and the upper temperature limit. Jour. phycol. ,1969 , $5350 \sim 358$

12 Hirose H ,Y Emoto. Studion wter die Thermalglora Von Japan Jour. Jap. Bot. $1940,16: 1 \sim 12$

13 Castenholz R W. Thermophilic blue green algae and thermal environment. Bact. Rev. 1969 $33: 476 \sim 500$

14 Hirose $\mathrm{H}$ et al. Illustrations of the Japanese fresh-water algae. 1977, 1 $\sim 156$

15 Copeland J J. Yellowstone thermal Myxophyceae ,Ann. New York : Acad. Sci. Press, 1936 36 : $\sim 232$ 